\title{
ADAPTAÇÃO FENOTÍPICA DE RAÍZES DE VÁRIAS PLANTAS COM FRUTOS DE DICTYOSPERMA RUBRA WENDL. \& DRUDE ENCONTRADOS NO SOLO*
}

\author{
WALTER RADAMES ACCORSI** \\ MYRTHES A.A. DE BARROS ***
}

\author{
RESUMO
}

Resumimos, neste trabalho, os resultados das observações sobre a adaptação fenotípica de raízes de várias plantas, tais como grama-batatais - Paspalum notatum, quebra-pedra ou erva-pombinha Phyllathus ninuri, maria-preta - Solanum nigrum, carurú - Amaranthus sp., tiririca - Cyperus rotundus e outras, com os frutos encontrados no solo da palmeira Dictyosperma rubra Wendl. \& Drude, cultivada como ornamental no Parque da Escola Superior de Agricultura "Luiz de Queiroz".

Essa adaptação caracteriza-se pela penetração das raízes através de orifícios circulares, existentes no pericarpo dos frutos, e produzidos por uma broca da família Bostriquide, da ordem Coleoptera. As raízes assim assemelham-se a um colar.

Diante desse fato, decidimos montar um experimento que nos permitisse elucidar o mecanismo dessa curiosa adaptação fenotípica.

\section{INTRODUÇÃO}

Ao coletarmos várias plantas que comumente vegetam ao redor da palmeira ornamental Dictyosperma rubra Wendl. \& Drude, cultivada no Parque da Escola, entre as quais a grama-batatais - Paspalum notatum, quebra-pedra ou erva-pompinha - Phyllanthus ninuri, mariapreta - Solanum nigrum, carurú - Amaranthus sp., tiririca - Cyperus rotundus e outras elpécies, verificamos a presença de diversos frutinhos da palmeira enfiados ao longo das raízes das plantas mencionadas, cujo número variava em cada raíz de um a muitos.

* Entregue para publicação em 31-12-1977.

** Prof. Chefe do Departamento de Botânica da ESALQ-USP.

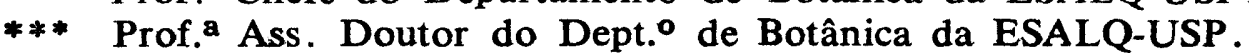


A quantidade de coquinhos ao redor da base do estipe e bem assim os enterrados no solo por ação dos tratos culturais, das regas e das chuvas, é enorme.

É natural que com o desenvolvimento do sistema radicular das citadas plantas, suas raízes encontrando os coquinhos com as perfurações, neles penetrassem, seja por haver maior concentração de umidade, seja pela presença de substâncias quimiotrópicas no endosperma.

Com c objetivo de esclarecer a referida adaptação fenotípica, cultivamos as mesmas plantas encontradas junto da palmeira em substrato adrede preparado, contendo camadas alternadas de frutos com camadas de solo.

\section{MATERIAL E MÉTODO}

O exame ao binocular do material coletado revelou que as raízes penetraram os coquinhos através de pequenas perfurações circulares existentes no pericarpo.

Dissecando-se os coquinhos, encontramos no seu interior larvas de um inseto. As lavras foram enviadas ao Departamento de Entomologia da Escola para a sua determinação e a informação que nos foi dada é que se trata de uma broca da família Bostriquide, ordem Coleoptera, ignorando-se, no momento, o gênero e a espécie.

Interessando-nos conhecer o processo de penetração das raízes nos coquinhos, montamos um experimento no Departamento de Botânica, colocando numa caixa grande de plástico várias camadas de solo, alternadas com camadas de coquinhos verdes, vermelhos e secos, colhidos no chão, junto às palmeiras. Sobre esse solo, transplantamos indivíduos jovens de quebra-pedra, maria-preta, carurú, tiririca, grama-batatais, todas com seus sistemas radiculares isentos de coquinhos.

Após três meses de cultivo, retiramos as plantas e procedemos ao exame de suas raízes, verificando-se que em nenhuma havia coquinhos enfiados. E isso porque os coquinhos não apresentavam perfurações produzidas no seu pericarpo e também porque o solo utilizado não proveio dos canteiros onde crescem as palmeiras e onde aparece a broca.

Pretendemos, oportunamente, repetir o experimento, mantendo todas as condições naturais do "habitat", para acompanharmos as fases sucesivas da penetração das raízes nos coquinhos.

\section{CONCLUSÕES}

A presença da larva da broca no interior dos coquinhos afasta a hipótese de serem as raízes as responsáveis pelas referidas perfurações, conforme o resultado do experimento. 
Com o desenvolvimento do sistema radicular das plantas utilizadas no experimento, suas raízes, encontrando coquinhos com perfurações, neles penetraram, seja por haver em seu interior maior concentração de umidade, seja por substâncias quimiotrópicas existentes no endosperma.

\section{$\therefore$ JMMARY}

\section{ADAPTATION OF ROOTS OF SEVERAL PLANTS WITH DICTYOSPERMA RUBRA WENDI, \& DRUDE FRUITS FOUND IN THE SOIL}

It was verified phenotypic adaptation of roots of several plants (Paspalum notatum, Phyllanthus minuri, Solanum nigrum, Amaranthus sp, Cyperus rotundus and others) with fruits found in the soil of the palm-tree Dictyosperma rubra Wendl. \& Drude cultivated as ornamental plant in the ESALQ park.

This adaptation characterized by the penetration of roots through the round orifices found in the fruit pericarp promoted by an insect of the Bostriquide family and Coleoptera category.

An experiment was realized in a plastic box with layers of soil alternated with layers of palm fruits without perfurations. It was used the same weeds found near of the palm-tree in the park. It was verified after three months that the roots did not perforate the fruits, showed that the insects was not present in the soil.

\section{LITERATURA CITADA}

EPSTEIN, E. 1975. Nutrição mineral das plantas: principios e perspectivas. Ed. Univ. S. Paulo/Livros Técnicos e Científicos Ed., Rio de Janeiro. 341 p.

BIDWELL, R.G.S. 1794. Plant Physiology. Macmillan Publi. Co. New York. $643 \mathrm{p}$.

SAliSBURY, F.B.; ROSS, C. 1969. Plant Physiology. Wadsworth Publ. Co., Belmont. 747 p. 


Este volume foi composto e impresso na canton * - setenta anos de experiência gráfica r. lopes coutinho, 164 - 291-2983 - 92-4496 - s. paulo 